\title{
Health-related quality of life as predictor for mortality in patients treated with long- term mechanical ventilation
}

\author{
Heidi Markussen ${ }^{1,2^{*}}$ (D) Sverre Lehmann ${ }^{1,3}$, Roy M. Nilsen ${ }^{4}$ and Gerd K. Natvig ${ }^{2}$
}

\begin{abstract}
Background: The Severe Respiratory Insufficiency (SRI) questionnaire is a specific measure of health-related quality of life (HRQoL) in patients treated with long-term mechanical ventilation (LTMV). The aim of the present study was to examine whether SRI sum scores and related subscales are associated with mortality in LTMV patients.

Methods: The study included 112 LTMV patients (non-invasive and invasive) from the Norwegian LTMV registry in Western Norway from 2008 with follow-up in August 2014. SRI data were obtained through a postal questionnaire, whereas mortality data were obtained from the Norwegian Cause of Death Registry. The SRI questionnaire contains 49 items and seven subscales added into a summary score (range 0-100) with higher scores indicating a better HRQoL. The association between the SRI score and mortality was estimated as hazard ratios (HRs) with 95\% confidence intervals $(95 \% \mathrm{Cl})$ using Cox regression models and HRs were estimated per one unit change in the SRI score.

Results: Of the 112 participating patients in 2008, 52 (46\%) had died by August 2014. The mortality rate was the highest in patients with chronic obstructive pulmonary disease (75\%), followed by patients with neuromuscular disease $(46 \%)$, obesity hypoventilation syndrome $(31 \%)$ and chest wall disease $(25 \%)(p<0.001)$. Higher SRI sum scores in 2008 were associated with a lower mortality risk after adjustment for age, education, hours a day on LTMV, time since initiation of LTMV, disease category and comorbidity (HR 0.98, 95\% Cl: 0.96-0.99). In addition, SRI-Physical Functioning (HR 0.98, 95\% Cl: 0.96-0.99), SRI-Psychological Well-Being (HR 0.98, 95\% Cl: 0.97-0.99), and SRl-Social Functioning (HR 0. 98, 95\% Cl: 0.97-0.99) remained significant risk factors for mortality after covariate adjustment. In the subgroup analyses of patient with neuromuscular diseases we found significant inverse associations between some of the SRI subscales and mortality.
\end{abstract}

Conclusions: SRI score is associated with mortality in LTMV-treated patients. We propose the use of SRI in the daily clinic with repeated measurements as part of individual follow-up. Randomized clinical trials with interventions aimed to improve HRQOL in LTMV patients should consider the SRI questionnaire as the standard HRQoL measurement.

Keywords: Long-term mechanical ventilation, Health-related quality of life, Predictors, Mortality, Survival, The severe respiratory insufficiency (SRI) questionnaire

\footnotetext{
* Correspondence: heidi.markussen@helse-bergen.no

${ }^{1}$ The Norwegian National Advisory Unit on Longterm Mechanical Ventilation, Department of Thoracic Medicine, Haukeland University Hospital, Jonas Lies vei $65, \mathrm{~N}-5021$ Bergen, Norway

${ }^{2}$ Department of Global Public Health and Primary Care, University in Bergen,

Kalfarveien 31, 5018 Bergen, Norway

Full list of author information is available at the end of the article
}

(c) The Author(s). 2019 Open Access This article is distributed under the terms of the Creative Commons Attribution 4.0 International License (http://creativecommons.org/licenses/by/4.0/), which permits unrestricted use, distribution, and reproduction in any medium, provided you give appropriate credit to the original author(s) and the source, provide a link to the Creative Commons license, and indicate if changes were made. The Creative Commons Public Domain Dedication waiver (http://creativecommons.org/publicdomain/zero/1.0/) applies to the data made available in this article, unless otherwise stated. 


\section{Background}

Chronic hypercapnic respiratory failure (CHRF) is a persistent state in which ventilation is insufficient to maintain a normal arterial pressure of carbon dioxide $\left(\mathrm{PaCO}_{2}\right)$ $[1,2]$. Long-term mechanical ventilation (LTMV) is a treatment for patients with CHRF due to different aetiologies and includes both non-invasive and invasive mechanical ventilation [2-4]. In adults, CHRF is mainly caused by the following four disease categories: neuromuscular diseases (NMD), chest wall diseases (CWD), obesity hypoventilation syndrome (OHS), and chronic obstructive pulmonary disease (COPD) [2-4]. The number of individuals treated with LTMV is increasing, and the largest growth has been observed in the use of a non-invasive connection to the ventilator through a mask or a mouthpiece $[2,3]$. One of the main goals of LTMV is to improve survival $[2,4]$. Due to ethical reasons, few randomized controlled trials (RCTs) comparing LTMV versus no LTMV treatment have been carried out in these patients $[2,3]$. One of the exceptions is RCTs involving COPD patients with CHRF, where the benefit of LTMV on survival has been and continues to be debated $[3,5,6]$. Two recent RCTs found improved one-year mortality in COPD patients treated with non-invasive LTMV $[7,8]$. In NMD patients LTMV has been well-established for several decades [2-4]. One of the few RCTs in this heterogenic category found improved mortality in patients with amyotrophic lateral sclerosis (ALS) [9].

Additionally, several observational studies and uncontrolled trials indicated that LTMV has a positive effect on survival in patients with NMD [10-16], OHS [10, 13, 17-20] and CWD [10-13, 21-23] relative to historical controls.

Self-reported health or health-related quality of life (HRQoL) has been shown to provide prognostic information for different groups [11, 24-27]. The Severe Respiratory Insufficiency (SRI) questionnaire was developed to specifically measure patient-reported HRQoL in patients receiving LTMV [28]. The role of SRI in predicting mortality in patients with CHRF has been examined during two three-year follow-up studies [29, 30]. In the first study, the clinical variables body mass index (BMI), leukocytes, base excess, forced expiratory volume in one second $\left(\mathrm{FEV}_{1}\right)$, and inspiratory vital capacity were included in the multivariate analysis [29]. The SRI score was associated with mortality in all patients except for those with COPD [29]. The second study found significant relationships between the SRI score and three-year mortality in LTMV patients with COPD and pulmonary tuberculosis sequelae after adjustment for $\mathrm{BMI}, \mathrm{PaCO}_{2}$ and forced vital capacity (FVC), but without subgroup analyses for the different diagnosis group [30]. Other measures of HRQoL, such as St. George's Respiratory Questionnaire (SGRQ) and the Maugeri Respiratory
Failure Questionnaire (MRF-28), were associated with mortality in LTMV-treated COPD patients from 21 study centres during 3 years of follow-up [26]. The SRI score's ability to predict mortality in patients treated with LTMV has been poorly investigated. Furthermore, findings are inconclusive [29, 30] and the associations have been investigated for only a limited time period (up to three years). Longer follow-up time might capture a more robust association due to higher mortality rates over time.

\section{Methods}

The main objective of the current study was to examine the association between HRQoL measured by the SRI questionnaire and all-cause mortality in LTMV patients over 80 months follow-up.

\section{Study population}

This study drew on resources from the Norwegian Registry for LTMV [31], the Norwegian Patient Registry [32], and the Norwegian Cause of Death Registry [33]. The registry data were linked by the personal identity number provided to all Norwegian citizens. The study was approved by the Regional Committee for Medical and Health Research Ethics number (273.06, 2012/ 1090-11) and the Norwegian Centre for Research Data (project number 16001). A written consent was a prerequisite from the Regional Committee for Medical and Health Research Ethics and the NPR to allow linking data between the registries. For cohort patients who died, exemption from the consent requirement for register connection to the Norwegian Patient Registry and Cause of Death Register was given.

The Norwegian Registry for LTMV was established in 2002 at Haukeland University Hospital, Bergen. The registry includes all patients in Norway who are treated with LTMV on a daily basis. The registry contains detailed information on patient characteristics, medical diagnosis, LTMV treatment and lung function. The registry has been described in detail previously [34, 35].

During the period of March to June 2008, patients in the Norwegian LTMV registry in Western Norway were invited to participate in the current study. The inclusion criteria were patients treated with non-invasive or invasive LTMV, over 18 years old and mentally able to answer additional study questions. Well-adapted LTMV treatment for at least 3 months was required for all participants. The invitation letter also included the SRI questionnaire, a form with questions on socioeconomic demographic conditions, and questions whether the patient had received help with completing the information.

Of 211 potential patients in the LTMV registry, 18 patients did not meet the inclusion criteria (Fig. 1). The remaining 193 eligible patients were invited to participate 


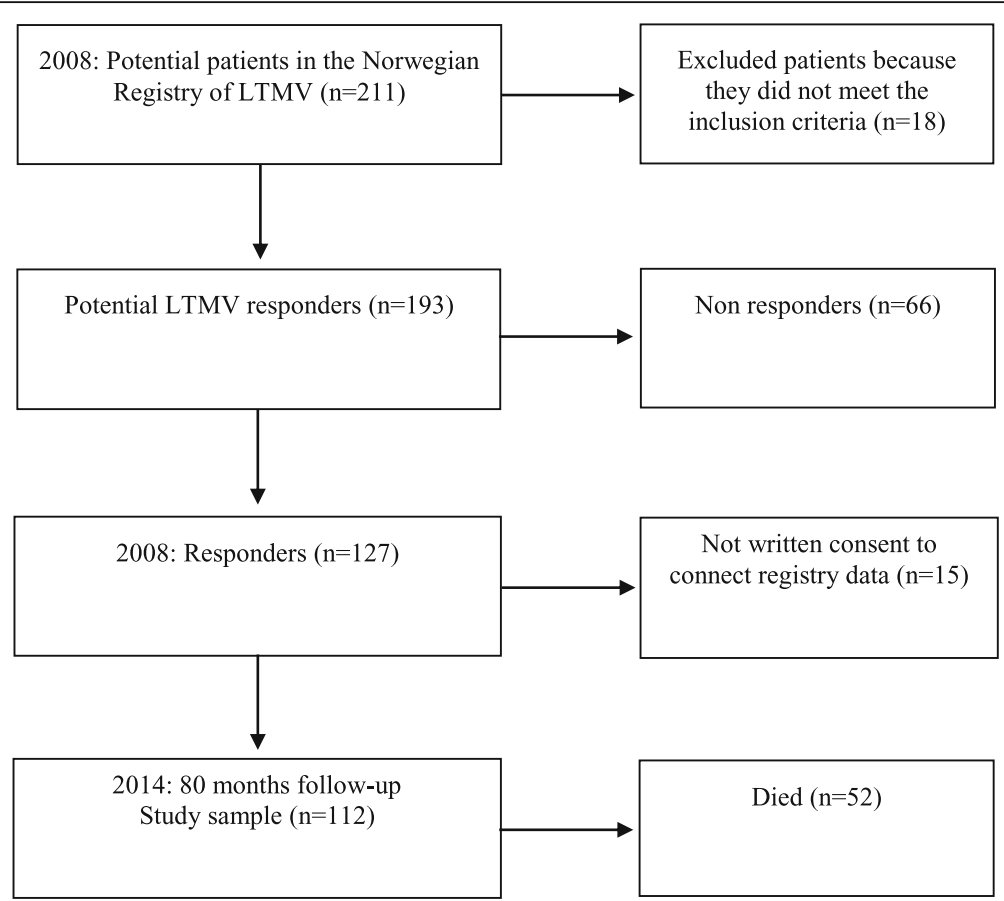

Fig. 1 Flow diagram of patients treated with long-term mechanical ventilation in the prospective cohort study from 2008 to 2014. Follow-up time was 80 months

in the study by postal mail, and $65 \%(n=127)$ consented to participate [34]. Of the 127 patients eligible for follow-up, written consent to connect comorbidity data from the NPR were not available from 15 of the patients. The reason for this were dementia or unable to answer the question $(n=3)$, had stopped using $\operatorname{LTMV}(n=8)$, unable to make contact $(n=1)$ or did not want to respond $(n=3)$. The disease category for these patients were NMD $(n=6)$, COPD $(n=2)$, OHS $(n=6)$ and CWD $(n=1)$, leaving a final study sample of 112 LTMV patients.

\section{The severe respiratory insufficiency (SRI) questionnaire}

Study participants were asked to complete the SRI questionnaire, which is a multidimensional questionnaire covering physical, psychological and social functioning. It was developed with a comprehensive methodology by physicians specialized in pulmonology and psychologists specialized in HRQoL and by open interviews with patients with CHRF treated with LTMV. The SRI questionnaire contains 49 items, and each item is categorized in one of the following seven subscales: SRI-Respiratory Complaints, SRI-Physical Functioning, SRI-Attendant Symptoms and sleep, SRI-Anxiety, SRI-Social Relationships, SRI-Social Functioning, or SRI-Psychological Well-Being. The subscales were added into a summary scale in which high values (range 0-100) indicate a better HRQoL [28]. The SRI questionnaire demonstrates very good psychometric qualities and has been validated and translated into several languages [2, 34-40]. The
SRI and MRF-28 questionnaires were recommended for research on HRQoL in patients treated with LTMV [41]. However, the reliability and validity in were better in the SRI compared to MRF-28 Questionnaire, Clinical COPD Questionnaire and Chronic Respiratory Questionnaire in patients with severe COPD treated with non-invasive LTMV [42]. The responsiveness of the SRI to changes in HRQoL after initiating non-invasive LTMV was superior to the generic questionnaire Short form-36 [43] and the SRI had the best ability to predict mortality compared to other HRQoL questionnaires [30]. The English validation study of the SRI included both non-invasive and invasive (tracheostomy) ventilated LTMV patients [37].

\section{All-cause mortality}

Information on the date of death was obtained from the Norwegian Cause of Death Registry in October 2014. The Cause of Death Registry covers all deaths in Norway and the deaths of Norwegian citizens who die abroad [33]. All deaths (approximately 40,000 each year) are reported by doctors, who are required to complete a standardized death certificate for each death [33].

\section{Other variables}

Based on previous research we also obtained data on educational level [44] and marital status [45]. Educational level was categorized as primary school, high school or college/university, and marital status was classified as married/cohabiting or single/divorced/widowed. Ventilator 
dependency was reported by the patients in hours a day they used the ventilator, the answer options were categorized as follow; less than $8 \mathrm{~h}, 8-12,12-24 \mathrm{~h}$ a day.

From the LTMV registry, we collected data on patient age, sex, treatment time since initiation of LTMV, FVC, $\mathrm{FEV}_{1}, \mathrm{PaCO}_{2}$, partial pressure of arterial oxygen $\left(\mathrm{PaO}_{2}\right)$ and main medical diagnosis, which was further categorized into NMD, COPD, OHS, and CWD. Studies have shown that comorbidity is a major prognostic factor in LTMV patients with NMD [13], COPD [46], OHS [18] and CWD [22]. Data concerning comorbidity were not available in the LTMV registry and were therefore collected from the Norwegian Patient Registry (NPR) [33], In this study, comorbidity was assessed similar to another study [47], as the number of somatic ICD-10 diagnosis codes at hospital discharge or an outpatient control for each patient during the recruitment period from March to June 2008.

\section{Statistical analysis}

Patient characteristics were quantified using descriptive statistics. The description was performed according to mean SRI sum score and to mortality status. We used the Kaplan-Meier survivor function with the log-rank test to describe the percentage of survivors according to disease groups (NMD, COPD, OHS and CWD).

The association between SRI and mortality was estimated as hazard ratios (HRs) with $95 \%$ confidence intervals (95\% CIs) using Cox regression models and HRs were estimated per one unit change in the SRI score. The time in months from study inclusion in 2008 (when baseline SRI was measured) until death was used as a measure of event-free time. All patients were followed up to 80 months until censoring, with August 30, 2014, as the final day of follow-up. We verified that the proportional hazards assumption was fulfilled for SRI, both in overall analyses and in subgroup analyses of NMD, COPD and OHS, by visual inspection of log-log plots. Subgroup analyses of CWD were not performed due to the small sample size.

The HRs with 95\% CIs were estimated both by crude and adjusted Cox regression models to control for variables that may potentially confound the true association between SRI and mortality. The adjustment variables included age, education, hours a day on LTMV, treatment time since initiation of LTMV, main disease category and comorbidity. We also evaluated $\mathrm{FEV}_{1}$ and FVC as confounding factors in the overall analyses of SRI. To avoid model overfitting in subgroup analysis of disease categories, only the most important covariates were included in the regression models (for NMD: age, hours a day on LTMV, and comorbidity; for COPD: age and comorbidity; for OHS: comorbidity only).
All statistical analyses were carried out using SPSS version 20 (SPSS Inc., Chicago, IL, USA) and Stata SE 14 (StataCorp LP, College Station, TX, USA) for Windows. All statistical tests were two-sided, and $p$ values lower than 0.05 were considered to be statistically significant.

\section{Results \\ Background characteristics}

The study sample comprised 112 LTMV-treated patients. Of these patients, 48 (43\%) were diagnosed with NMD, 24 (21\%) with COPD, 32 (29\%) with OHS, and 8 (7\%) with CWD. At baseline, 103 (92\%) patients received non-invasive LTMV, whereas 9 (8\%) patients, with NMD, were ventilated invasively via tracheostomy. The mean BMI $(n=71)$ was 27.1 (9.5) in NMD patients, 29.2 (9.1) in COPD patients, 40.6 (7.7) in OHS patients, and $22.5(5.1) \mathrm{kg} / \mathrm{m}^{2}$ in CWD patients.

The baseline mean SRI sum score varied considerably by sex, age group, education level, LTMV hours a day, years on LTMV, disease category and comorbidity (Table 1$)$. The SRI sum score in invasively $(n=10)$ and non-invasively $(n=117)$ ventilated patients was $57.0(16.2)$ and 58.0 (18.8), respectively. Assistance to complete the SRI questionnaire was reported by $26 \%$ of the study participants.

Among the respiratory variables, baseline $\mathrm{FEV}_{1}$ and FVC correlated significantly with all SRI subscales except for SRI-Attendant symptoms and sleep scale and SRI-Social Functioning (Additional file 1: Table S1). Baseline $\mathrm{PaO}_{2}$ correlated significantly with SRI-Physical Functioning only. All participants were receiving ventilation treatment at study start, and $\mathrm{PaCO}_{2}$ levels were therefore normalized at baseline. An inverse correlation between baseline $\mathrm{PaCO}_{2}$ and SRI-Social Relationships was present, but no other associations were found for the SRI sum score or for any of the six remaining SRI subscales (Additional file 1: Table S1).

During the 80 months of follow-up, 52 (46\%) patients died (Fig. 1). By Kaplan-Meier survival analyses (Fig. 2), we found that patients with COPD had the highest overall mortality rate (75\%), followed by patients with NMD (46\%), OHS (31\%) and CWD (25\%) $(p<0.001)$ (Fig. 2). The mortality rates differed between age groups, education levels, LTMV hours a day, years on LTMV, disease categories and burden of comorbidity (Table 2), but not between men and women $(p=0.88)$, and between married /cohabiting and single/divorced/widowed $(p=0.91)$. We found significant differences between survivors and deceased patients in baseline mean $\mathrm{FEV}_{1}$ and FVC (both $\mathrm{p}<0.001$ ), and a minor difference in $\mathrm{PaO}_{2}$ that was not statistically significant (Table 2). There was no significant difference in $\mathrm{PaCO}_{2}$ between the survivors and deceased patients (Table 2). 
Table 1 Baseline sum score of the Severe Respiratory Insufficiency questionnaire by background characteristics in 112 patients treated with long-term mechanical ventilation between 2008 and 2014

\begin{tabular}{|c|c|c|}
\hline Characteristic & $\begin{array}{l}\text { Participants, } \mathrm{n}^{\mathrm{a}} \\
(n=112)\end{array}$ & $\begin{array}{l}\text { SRI-SS } \\
\text { Baseline (2008 } \\
\text { mean (SD) }\end{array}$ \\
\hline \multicolumn{3}{|l|}{ Sex } \\
\hline Female & 48 & $51.4(16.7)$ \\
\hline Male & 57 & $57.7(19.5)$ \\
\hline \multicolumn{3}{|l|}{ Age } \\
\hline$\leq 60$ & 37 & $59.0(16.7)$ \\
\hline$>60$ & 68 & $52.5(19.2)$ \\
\hline \multicolumn{3}{|l|}{ Education } \\
\hline Primary school & 31 & $50.0(20.5)$ \\
\hline High school & 41 & $52.2(16.0)$ \\
\hline College/university & 33 & $62.5(17.6)$ \\
\hline \multicolumn{3}{|l|}{ Marital status } \\
\hline Married /cohabiting & 60 & $54.7(19.1)$ \\
\hline Single/divorced/widowed & 45 & $54.9(18.0)$ \\
\hline \multicolumn{3}{|l|}{ LTMV h/day } \\
\hline $5-8$ & 45 & $57.9(18.3)$ \\
\hline $8-12$ & 42 & $55.2(18.8)$ \\
\hline $12-24$ & 16 & $44.9(17.1)$ \\
\hline \multicolumn{3}{|l|}{ Years on LTMV } \\
\hline$\leq 4$ & 60 & $51.9(18.2)$ \\
\hline$>4$ & 45 & $58.6(18.4)$ \\
\hline \multicolumn{3}{|l|}{ Disease } \\
\hline NMD & 43 & $60.0(14.8)$ \\
\hline COPD & 23 & $41.1(18.3)$ \\
\hline $\mathrm{OHS}$ & 31 & $58.0(18.5)$ \\
\hline CWD & 8 & $54.3(21.1)$ \\
\hline \multicolumn{3}{|l|}{ Co-morbidity } \\
\hline No additionally diagnosis & 41 & $60.2(17.6)$ \\
\hline 1 additionally diagnosis & 28 & $55.7(17.9)$ \\
\hline$\geq 2$ additionally diagnosis & 36 & $48.0(18.3)$ \\
\hline
\end{tabular}

Abbreviations: SRI-SS, Severe Respiratory Insufficiency sum score; SD, standard deviation; $\mathrm{Cl}$, confidence interval; LTMV, long-term mechanical ventilation; NMD, neuro muscular disease; COPD, chronic obstructive pulmonary disease; $\mathrm{OHS}$, obesity hypoventilation syndrome; CWD, chest wall diseasese

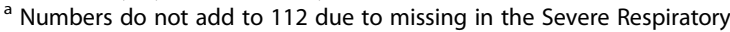
Insufficiency questionnaire, as well as missing in education level, marital status and daily hours on LTMV responses

\section{SRI sum and subscales in relation to mortality}

Crude analyses of baseline SRI showed significantly higher mean values among the survivors compared to the deceased for the SRI sum score and SRI subscales except in the SRI-Attendant symptoms and sleep scale (Table 3).

The association between the SRI sum score and mortality remained significant after adjustment for age, education level, hours a day on LTMV, treatment time since initiation of LTMV, disease category and comorbidity (HR 0.98, 95\% CI: 0.96-0.99). In addition, SRI-Physical Functioning (HR 0.98, 95\% CI: 0.96-0.99), SRI-Psychological Well-Being (HR 0.98, 95\% CI: 0.970.99), and SRI-Social Functioning (HR 0.98, 95\% CI: 0.97-0.99) remained significant risk factors for mortality after covariate adjustment (Table 4). Additional adjustment for baseline FVC and $\mathrm{FEV}_{1}$ did not alter the results much for SRI sum score (adjustment for FVC: HR 0.97, 95\% CI: 0.94, 0.99); adjustment for $\mathrm{FEV}_{1}$ : $\mathrm{HR} 0.97,95 \%$ CI 0.94, 0.99).

Among NMD patients, SRI-Physical Functioning (HR 0.97, 95\% CI: 0.94-1.00), SRI-Psychological Well-Being (HR 0.97, 95\% CI: 0.95-0.99) and SRI-Social Functioning (HR 0.97, 95\% CI: 0.94-0.99) remained significant factors for mortality after adjustment for age, hours a day on LTMV and comorbidity (Table 5).

In COPD patients, SRI-Attendant Symptoms and Sleep (HR 0.97, 95\% CI: 0.94-1.00) and SRI-Psychological Well-Being (HR 0.98, 95\% CI: 0.96-1.00) remained associated with mortality after adjustment for age and comorbidity (Table 6). The SRI sum score or subscales were not associated with mortality among patients with OHS (Additional file 1: Table S2).

\section{Discussion}

We found that HRQoL, as measured by the SRI questionnaire, was inversely associated with mortality in LTMV patients before and after adjustment for covariates. In the total group of LTMV patients, the adjusted analyses showed significant inverse associations between mortality and the SRI sum score and the SRI subscales, 'physical functioning, 'social functioning' and 'psychological well-being'. Furthermore, mortality varied considerably between the disease groups during the six-year period. The highest mortality was among COPD patients with established CHRF receiving LTMV. The majority of mortality in COPD is related to cardiac disease and the requirement of LTMV in COPD might be understood as a marker of overall frailty and multi-system disease severity. The lowest mortality was in the CWD group, reflecting the non-progressive nature of the disease in these patients.

As shown in previous studies [3, 10-13, 23], mortality in patients treated with LTMV is associated with underlying disease categories. Previous studies have shown large variations in the attending patient categories, severity of disease, and follow-up times. Thus, a direct comparison of mortality between studies on patients with LTMV is challenging and might lead to an oversimplification.

\section{HRQoL as a prognostic factor}

The association between poor HRQoL and increased mortality in the total group of LTMV patients is consistent with the main findings of other similar studies on 


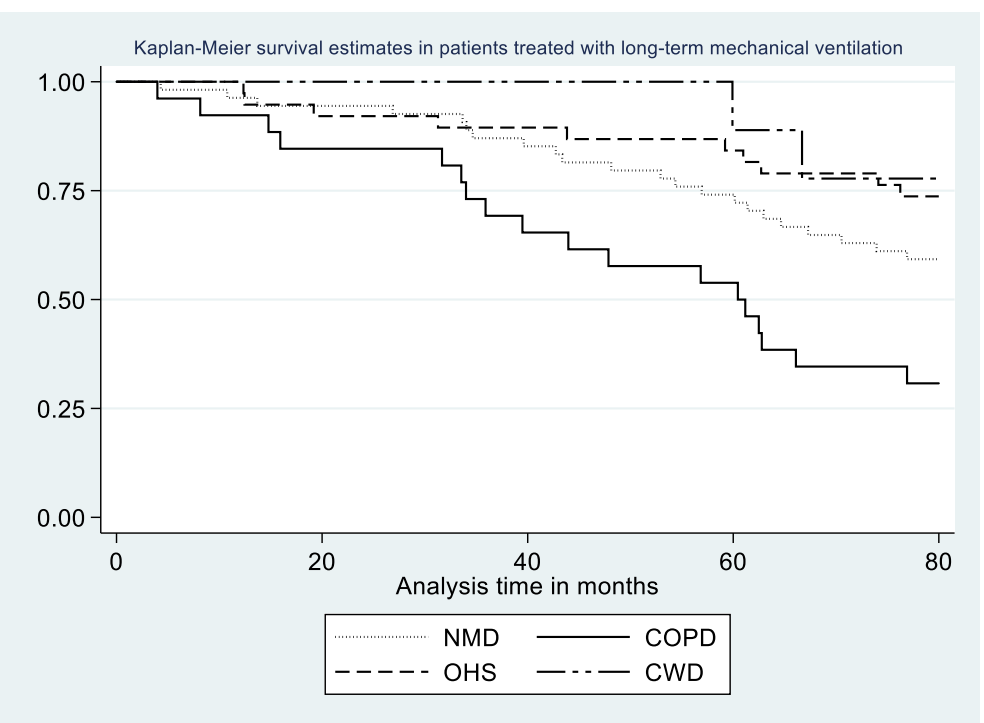

Fig. 2 Kaplan-Meier survival estimates in patients treated with long-term mechanical ventilation between 2008 and 2014 . Follow-up time was 80 months. Abbreviations: NMD, neuro muscular disease; COPD, chronic obstructive pulmonary disease; OHS, obesity hypoventilation syndrome; CWD, chest wall diseasese

LTMV patients [30, 31]. In line with Budweiser (2007a), crude analyses of SRI were significantly associated with mortality in all SRI subscales, with the exception of the 'attendant symptoms and sleep' scale.

The adjusted analyses among NMD patients showed that SRI 'physical functioning,' 'psychological well-being' and 'social functioning' continued to be significant factors for mortality, which was consistent with the study by Budweiser [30], but with different adjustment variables than those in our study. We also found associations between SRI and mortality among COPD patients in the adjusted analyses in the 'attendant symptoms and sleep' and 'psychological well-being' SRI subscales.

The initial choice of the adjustment variables in the present study was based on previous work that evaluated age $[10,15,26,45]$, sex $[18,48]$, education level [44], marital status [45], disease categories (NMD, COPD, OHS and CWD) $[2,3,10-13,23]$ and comorbidity [13, 18, 22, 46]. The variables ventilator dependency and time since LTMV was initiated were chosen a priori. Marital status was not associated with neither mortality nor the SRI sum score and was therefore excluded as adjustment variable. There were no sex differences between survivors and those who deceased, thus sex also was excluded as an adjustment variable.

However, we have considered the possibility that HRQoL could be influenced by other confounding covariates that might also pose a risk of death, such as $\mathrm{PaCO}_{2}$. Reduced $\mathrm{PaCO}_{2}$ levels have been related to lower one-year mortality and improved SRI scores in COPD patients treated with LTMV $[7,8]$. On the other hand, exploratory analyses did not identify any significant correlations between changes in hypercapnia status or baseline hypercapnia status and mortality in this group [5]. However, in the present study, $\mathrm{PaCO}_{2}$ values were normalized at baseline as a result of ongoing LTMV and were therefore not included in the analyses. The results from studies on lung function and survival in LTMV patients are not conclusive. Some studies $[19,23,30]$ reported associations between low $\mathrm{FEV}_{1}$ and $\mathrm{FVC}$ and mortality, whereas another study [11] found no differences in baseline lung function between the survivors and deceased patients. When FVC and $\mathrm{FEV}_{1}$ were added to the Cox regression analysis in the current study, the result was altered only slightly; however, this result might also be influenced by missing lung function data (FVC baseline numbers did not sum to 112 due to 23 missing data points, $\mathrm{FEV}_{1}$ baseline numbers did not sum to 112 due to 22 missing data points), some of the missing data might be explained due to patients having difficulties performing the spirometry test.

We also considered to include ventilation mode as a covariate as longer survival were reported in patients with DMD using non-invasive LTMV compared to those receiving LTMV via a tracheostomy $[14,49]$. However, another study concluded that the risk of death was not associated with use of invasive versus non-invasive LTMV in patients with DMD [16], No significant difference in one year mortality was found between patients receiving LTMV via a tracheostomy and those weaned after discharged from the Intensive Care Unit (ICU) and no significant difference in HRQoL measured by SRI at 
Table 2 Background variables at baseline in the survivors and deceased individuals treated with LTMV between 2008 and 2014

\begin{tabular}{|c|c|c|c|}
\hline Characteristic & All participants, $\mathrm{n}(n=112)$ & Survivors, $\mathrm{n}(\%)(n=60)$ & Deceased, n (\%) $(n=52)$ \\
\hline \multicolumn{4}{|l|}{ Sex } \\
\hline Female & 53 & $28(53)$ & $25(47)$ \\
\hline Male & 59 & $32(54)$ & $27(46)$ \\
\hline \multicolumn{4}{|l|}{ Age } \\
\hline$\leq 60$ & 38 & $26(68)$ & $12(32)$ \\
\hline$>60$ & 74 & $34(46)$ & $40(54)$ \\
\hline \multicolumn{4}{|l|}{ Education } \\
\hline Primary school & 33 & $18(55)$ & $15(45)$ \\
\hline High school & 44 & $23(52)$ & $21(48)$ \\
\hline College/university & 35 & $19(54)$ & $16(46)$ \\
\hline \multicolumn{4}{|l|}{ Marital status } \\
\hline Married /cohabiting & 64 & $34(53)$ & $30(47)$ \\
\hline Single/divorced/widowed & 48 & $26(54)$ & $22(46)$ \\
\hline \multicolumn{4}{|l|}{ LTMV h/day ${ }^{a}$} \\
\hline $5-8$ & 50 & $33(66)$ & $17(34)$ \\
\hline $8-12$ & 42 & $23(55)$ & $19(45)$ \\
\hline $12-24$ & 17 & $2(12)$ & $15(88)$ \\
\hline \multicolumn{4}{|l|}{ Years on LTMV } \\
\hline$\leq 4$ & 65 & $33(51)$ & $32(49)$ \\
\hline$>4$ & 47 & $27(57)$ & $20(43)$ \\
\hline \multicolumn{4}{|l|}{ Disease } \\
\hline NMD & 48 & $26(54)$ & $22(46)$ \\
\hline COPD & 24 & $6(25)$ & $18(75)$ \\
\hline $\mathrm{OHS}$ & 32 & $22(69)$ & $10(31)$ \\
\hline CWD & 8 & $6(75)$ & $2(25)$ \\
\hline \multicolumn{4}{|l|}{ Co-morbidity } \\
\hline No additionally diagnosis & 44 & $32(73)$ & $12(27)$ \\
\hline 1 additionally diagnosis & 29 & $18(62)$ & $11(38)$ \\
\hline$\geq 2$ additionally diagnosis & 39 & $10(26)$ & $29(74)$ \\
\hline \multicolumn{4}{|l|}{ Respiratory $^{\mathrm{a}}$} \\
\hline FVC (litre) (mean, SD) & 89 & $2.64(1.15)$ & $1.89(0.93)$ \\
\hline FEV1 (litre) (mean, SD) & 90 & $1.88(1.04)$ & $1.16(0.70)$ \\
\hline $\mathrm{PaCO}_{2} \mathrm{kPa}$ daytime (mean, SD) & 84 & $5.61(0.76)$ & $6.01(1.06)$ \\
\hline $\mathrm{PaO}_{2} \mathrm{kPa}$ daytime (mean, SD) & 69 & $10.1(1.78)$ & $9.14(1.92)$ \\
\hline
\end{tabular}

Abbreviations: LTMV, long-term mechanical ventilation; NMD, neuro muscular disease; COPD, chronic obstructive pulmonary disease; OHS, obesity hypoventilation syndrome; $\mathrm{CWD}$, chest wall disorders; $\mathrm{FVC}$, forced vital capacity; $\mathrm{FEV}_{1}$, forced expiratory volume in one second; $\mathrm{PaCO}_{2}$, partial pressure of arterial carbon dioxide; $\mathrm{PaO}_{2}$, partial pressure of arterial oxygen

${ }^{a}$ Numbers do not add to 112 due to missing in daily hours on LTMV and respiratory variables

discharge from ICU were found between the two groups [50]. However, HRQoL tended to be lower, in the SRI 'physical functioning', while scores for 'anxieties' tended to be better in patients receiving LTMV via tracheostomy compared to those treated with non-invasive LTMV [51].

Although the analyses in the present study were adjusted for education level, other economic confounding variables, such as income, might also have an impact on
HRQoL and mortality. On the other hand, Norwegian society and health care services probably represent one of the most equitable systems worldwide, where all citizens have equal access to health care services. Nevertheless, the number of covariates that could be included in the analyses in this study was limited by the sample size at baseline, and we can never exhaustively cover all variables of minor importance among LTMV patients. 
Table 3 Mean baseline scores (both sum score and subscales) of the Severe Respiratory Insufficiency questionnaire in patients treated with long-term mechanical ventilation between 2008 and 2014

\begin{tabular}{|c|c|c|c|c|c|}
\hline \multirow[t]{2}{*}{ SRI } & \multicolumn{2}{|c|}{ Survivors $(n=60)$} & \multirow[b]{2}{*}{$\mathrm{n}^{\mathrm{a}}$} & \multirow{2}{*}{$\begin{array}{l}\text { Deceased }(n=52) \\
\text { mean }(S D)\end{array}$} & \multirow{2}{*}{$\begin{array}{l}P \\
\text { value }\end{array}$} \\
\hline & $\overline{n^{a}}$ & mean (SD) & & & \\
\hline SRI- Sum Score (SS) & 58 & $60.0(18.3)$ & 47 & $48.4(16.8)$ & 0.001 \\
\hline SRI- Physical Functioning (PF) & 59 & $45.9(23.0)$ & 50 & $26.9(21.3)$ & $<0.001$ \\
\hline SRI- Respiratory Complaints (RC) & 59 & $61.0(22.4)$ & 50 & $51.1(22.6)$ & 0.02 \\
\hline SRI- Attendant Symptoms and Sleep (AS) & 59 & $53.3(20.1)$ & 50 & $55.8(20.2)$ & 0.53 \\
\hline SRI- Social Relationships (SR) & 59 & $70.7(24.4)$ & 49 & $59.0(21.8)$ & 0.01 \\
\hline SRI- Anxiety (AX) & 59 & $64.2(27.5)$ & 49 & $52.9(27.2)$ & 0.03 \\
\hline SRI- Psychological Well-Being (WB) & 58 & $66.2(22.0)$ & 47 & $52.3(22.9)$ & 0.002 \\
\hline SRI- Social Functioning (SF) & 59 & $56.5(24.6)$ & 49 & $39.1(18.7)$ & $<0.001$ \\
\hline
\end{tabular}

Abbreviations: SRI, Severe Respiratory Insufficiency; SD, standard deviation

${ }^{a}$ Numbers do not add to 60 and 52 due to missing in the Severe Respiratory Insufficiency questionnaire

${ }^{b}$ By two-sample t-test

\section{Why and how SRI predicts mortality}

Previous studies using patient-reported measures other than SRI have also reported an association between self-reported health and mortality in patients treated with LTMV [11, 26]. However, these studies did not adjust for the same covariates as the present study, and they lacked important variables, such as comorbidity and education level. There is a large body of evidence on the association between self-reported health measures and mortality in other settings and disorders, such as in communities [24], in patients with cancer [25] and idiopathic pulmonary fibrosis [27]. Explanations of these consistent findings are complex and imply that survey respondents' perceptions of health status are holistic; they include information on medical status but that information might be evaluated differently by men and women in different social positions, with different reference groups providing different social comparisons [24]. Further, the accuracy of self-reported health as a predictor of mortality depends on the comprehensiveness and accuracy of the information that the person incorporates into the self-rating [52]. This hypothesis corresponds with SRI as a multidimensional comprehensive questionnaire that captures the symptoms of CHRF and covers essential aspects of LTMV patients' daily life [28].

\section{Clinical implication of the associations between SRI and mortality}

Individuals suffering from CHRF treated with LTMV often have an incurable disease [2-4]. Health care professionals and relatives tend to behave differently depending on whether the disease is perceived as a chronic or terminal condition. However, the distinction between the patient's condition as chronic or terminal might become vague and can sometimes be ambiguous and difficult to interpret [53]. Prognostic information from the SRI questionnaire might provide valuable knowledge on how to cope with these situations, improving treatment plans and communication between involved professionals, family members, and the LTMV patient. Our study demonstrates that the

Table 4 Hazard ratios for mortality by baseline scores (both sum score and subscales) of the Severe Respiratory Insufficiency questionnaire in all patients $(n=112)$ treated with long-term mechanical ventilation between 2008 and 2014

\begin{tabular}{|c|c|c|c|c|c|c|c|}
\hline \multirow[t]{2}{*}{ SRI } & \multirow[b]{2}{*}{$\mathrm{N}^{\mathrm{b}}$} & \multicolumn{3}{|c|}{ Crude } & \multicolumn{3}{|c|}{ Adjusted $^{a}$} \\
\hline & & $\overline{\mathrm{HR}}$ & $95 \% \mathrm{Cl}$ & $P$ value & $\overline{\mathrm{HR}}$ & $95 \% \mathrm{Cl}$ & $P$ value \\
\hline SRI- Sum Score (SS) & 103 & 0.97 & $(0.95,0.98)$ & 0.001 & 0.98 & $(0.96,0.99)$ & 0.04 \\
\hline SRI- Physical Functioning (PF) & 107 & 0.97 & $(0.95,0.98)$ & $<0.001$ & 0.98 & $(0.96,0.99)$ & 0.007 \\
\hline SRI- Respiratory Complaints (RC) & 107 & 0.98 & $(0.97,0.99)$ & 0.01 & 0.99 & $(0.98,1.01)$ & 0.28 \\
\hline SRI- Attendant Symptoms and Sleep (AS) & 107 & 1.00 & $(0.99,1.02)$ & 0.50 & 0.99 & $(0.98,1.01)$ & 0.64 \\
\hline SRI- Social Relationships (SR) & 106 & 0.98 & $(0.97,0.99)$ & 0.009 & 0.99 & $(0.98,1.00)$ & 0.14 \\
\hline SRI- Anxiety (AX) & 106 & 0.99 & $(0.99,1.00)$ & 0.03 & 0.99 & $(0.98,1.00)$ & 0.25 \\
\hline SRI- Psychological Well-Being (WB) & 103 & 0.98 & $(0.97,0.99)$ & 0.001 & 0.98 & $(0.97,0.99)$ & 0.009 \\
\hline SRI- Social Functioning (SF) & 106 & 0.97 & $(0.96,0.99)$ & $<0.001$ & 0.98 & $(0.97,0.99)$ & 0.02 \\
\hline
\end{tabular}

Abbreviations: SRI Severe Respiratory Insufficiency, $H R$ hazard ratio, $\mathrm{Cl}$ confidence interval

${ }^{a}$ Adjusted for age, education level, daily hours on LTMV, treatment time since initiation of LTMV, disease category and comorbidity

${ }^{b}$ Numbers do not add to 112 due to missing in the Severe Respiratory Insufficiency questionnaire 
Table 5 Hazard ratios for mortality by baseline scores (both sum score and sub-scales) of the Severe Respiratory Insufficiency questionnaire in neuromuscular patients $(n=48)$ treated with long-term mechanical ventilation between 2008 and 2014

\begin{tabular}{|c|c|c|c|c|c|c|c|}
\hline \multirow[t]{2}{*}{$\overline{\text { SRI }}$} & \multirow[b]{2}{*}{$N^{b}$} & \multicolumn{3}{|c|}{ Crude } & \multicolumn{3}{|c|}{ Adjusted $^{a}$} \\
\hline & & $\overline{\mathrm{HR}}$ & $95 \% \mathrm{Cl}$ & $P$ value & $\overline{\mathrm{HR}}$ & $95 \% \mathrm{Cl}$ & $P$ value \\
\hline SRI- Sum Score (SS) & 43 & 0.97 & $(0.94,1.00)$ & 0.09 & 0.97 & $(0.93,1.01)$ & 0.16 \\
\hline SRI- Physical Functioning (PF) & 46 & 0.97 & $(0.94,0.99)$ & 0.008 & 0.97 & $(0.95,1.00)$ & 0.05 \\
\hline SRI- Respiratory Complaints (RC) & 45 & 1.00 & $(0.98,1.02)$ & 0.88 & 0.99 & $(0.97,1.02)$ & 0.67 \\
\hline SRI- Attendant Symptoms and Sleep (AS) & 45 & 1.01 & $(0.99,1.03)$ & 0.20 & 1.00 & $(0.98,1.03)$ & 0.43 \\
\hline SRI- Social Relationships (SR) & 45 & 0.98 & $(0.96,1.00)$ & 0.14 & 0.99 & $(0.96,1.01)$ & 0.30 \\
\hline SRI- Anxiety (AX) & 45 & 0.99 & $(0.98,1.01)$ & 0.46 & 0.99 & $(0.97,1.01)$ & 0.32 \\
\hline SRI- Psychological Well-Being (WB) & 43 & 0.98 & $(0.96,1.00)$ & 0.08 & 0.97 & $(0.95,0.99)$ & 0.03 \\
\hline SRI- Social Functioning (SF) & 44 & 0.96 & $(0.94,0.99)$ & 0.002 & 0.97 & $(0.94,0.99)$ & 0.02 \\
\hline
\end{tabular}

Abbreviations: SRI Severe Respiratory Insufficiency, $H R$ hazard ratio, $\mathrm{Cl}$ confidence interval

${ }^{\text {a }}$ Adjusted for age, daily hours on LTMV and comorbidity

${ }^{\mathrm{b}}$ Numbers do not add to 48 due to missing in the Severe Respiratory Insufficiency questionnaire

risk of death decreases by each unit increase in the SRI score. This result suggests that LTMV patients with low SRI should be identified, initiating thorough considerations on how to improve HRQoL. However, whether the relationship between mortality and quality of life is causal and changes in HRQoL status in some way influences mortality cannot be confirmed in this study design.

The minimal clinically important difference of the SRI questionnaire has not been defined [41]. However, the great numerical difference in SRI score at baseline between the surviving LTMV patients and those who died during the follow-up, support the clinical relevance of the study.

\section{Strengths and limitations}

As far as we are aware, this study is among the very first to examine SRI scores as a predictor for mortality in LTMV patients with a follow-up time as long as 80 months. The strengths of the study include the use of standardized data collection [32-34], including relevant confounders, such as comorbidity, which is often lacking in study of this type, and the prospective study design. Another strength is the use of the specific and validated SRI questionnaire, which can capture HRQoL related to symptoms and the experience of having CHRF and LTMV [2, 28-30, 34-43].

The study has some limitations. First, its small sample size may decrease the statistical power to detect clinically relevant associations in multivariate Cox analyses. Second, comorbidity modeled simply as the number of somatic diagnoses. Charlson Comorbidity Index [54] is a common index to measure comorbidity using ICD-10 codes. However, as complete ICD-10 codes were not available in our data, we chose to measure comorbidity as the number of somatic diagnoses. Thirdly, some of the LTMV patients answered that they received help to complete the questionnaire, which might introduce some information bias in SRI scores. However, it is of

Table 6 Hazard ratios for mortality by baseline scores (both sum score and sub-scales) of the Severe Respiratory Insufficiency questionnaire in chronic obstructive pulmonary disease patients $(n=24)$ treated with long-term mechanical ventilation between 2008 and 2014

\begin{tabular}{|c|c|c|c|c|c|c|c|}
\hline \multirow[t]{2}{*}{ SRI } & \multirow[b]{2}{*}{$N^{b}$} & \multicolumn{3}{|c|}{ Crude } & \multicolumn{3}{|c|}{ Adjusted $^{a}$} \\
\hline & & $\mathrm{HR}$ & $95 \% \mathrm{Cl}$ & $P$ value & $\mathrm{HR}$ & $95 \% \mathrm{Cl}$ & $P$ value \\
\hline SRI- Sum Score (SS) & 23 & 0.98 & $(0.95,1.01)$ & 0.14 & 0.97 & $(0.95,1.01)$ & 0.19 \\
\hline SRI- Physical Functioning (PF) & 23 & 0.98 & $(0.95,1.01)$ & 0.16 & 0.97 & $(0.93,1.01)$ & 0.13 \\
\hline SRI- Respiratory Complaints (RC) & 23 & 0.98 & $(0.95,1.01)$ & 0.33 & 0.98 & $(0.95,1.01)$ & 0.26 \\
\hline SRI- Attendant Symptoms and Sleep (AS) & 23 & 0.98 & $(0.96,1.01)$ & 0.15 & 0.97 & $(0.95,1.00)$ & 0.10 \\
\hline SRI- Social Relationships (SR) & 23 & 0.99 & $(0.97,1.01)$ & 0.08 & 0.98 & $(0.99,1.01)$ & 0.37 \\
\hline SRI- Anxiety (AX) & 23 & 0.99 & $(0.97,1.01)$ & 0.32 & 0.99 & $(0.971 .01)$ & 0.34 \\
\hline SRI- Psychological Well-Being (WB) & 23 & 0.98 & $(0.96,1.00)$ & 0.07 & 0.98 & $(0.96,1.00)$ & 0.13 \\
\hline SRI- Social Functioning (SF) & 23 & 0.99 & $(0.97,1.01)$ & 0.50 & 0.99 & $(0.97,1.01)$ & 0.64 \\
\hline
\end{tabular}

Abbreviations: SRI Severe Respiratory Insufficiency, $H R$ hazard ratio, $\mathrm{Cl}$ confidence interval

a Adjusted for age and comorbidity

${ }^{b}$ Numbers do not add to 24 due to missing in the Severe Respiratory Insufficiency questionnaire 
great importance to include the SRI scores from patients who needed help to fill out the questionnaire.

In addition, because of the observational study design, we cannot exclude the possibility of residual or unknown confounding. Whether HRQoL score reflects a perception by the LTMV patient of progression of her or his condition or whether change in HRQoL status in some way also influences the course of the condition is an interesting question. However, the research design cannot confirm causality between improvement in HRQoL and survival in this study. To address this question a randomized interventional study aiming to improve HRQoL with a control group receiving standard treatment would be more suitable.

\section{Conclusion}

This study suggests that SRI is an important factor in prognostic mortality models in LTMV-treated patients. The design and data do not allow us to imply any causal relationships between a change in HRQoL and a change in mortality. We propose an active use of the SRI questionnaire in the daily clinic with repeated measurements as part of individual follow-up. Future studies on this topic should be larger and preferably organized as multicentre long-term RCTs, including specific interventions aimed at improving HRQoL in LTMV patients, compared to standard care. Even if there is no comparison in this paper made between SRI and other quality of life measures, we suggest SRI to be used as the quality of life measure in the studies to come.

\section{Additional file}

Additional file 1: Table S1. Correlation between baseline scores (both sum score and subscales) of the Severe Respiratory Insufficiency questionnaire and respiratory variables in 112 patients treated with longterm mechanical ventilation between 2008 and 2014. Table S2. Hazard ratios for mortality by baseline scores (both sum score and subscales) of the Severe Respiratory Insufficiency questionnaire in obesity hypoventilation syndrome patients $(n=32)$ treated with long-term mechanical ventilation between 2008 and 2014. (DOCX 68 kb)

\section{Abbreviations \\ BMl: Body mass index; CHRF: Chronic hypercapnic respiratory failure; Cl: Confidence interval; COPD: Chronic obstructive pulmonary disease; CWD: Chest wall disease; $\mathrm{FEV}_{1}$ : Forced expiratory volume in one second of expiration; FVC: Forced vital capacity; HR: Hazard ratio; HRQoL: Health-related quality of life; LTMV: Long-term mechanical ventilation; NMD: Neuromuscular disease; $\mathrm{OHS}$ : Obesity hypoventilation syndrome; $\mathrm{PaCO}_{2}$ : Arterial partial pressure of carbon dioxide; SD: Standard deviation; SRI questionnaire: Severe Respiratory Insufficiency questionnaire}

\section{Acknowledgements}

We thank the Norwegian National Advisory Unit on Long-term Mechanical Ventilation and the Norwegian Registry for Long-Term Mechanical Ventilation, Department of Thoracic Medicine, Haukeland University Hospital. The register is funded by the Western Norway Regional Health Authority. We also thank the Norwegian Patient Registry and the Norwegian Cause of Death Registry.

\section{Funding}

Study funding was partly provided by the Norwegian National Advisory Unit on Long-term Mechanical Ventilation, Department of Thoracic Medicine, Haukeland University Hospital. In the design of the study there were no funding, data collection was partly funded from the Department of Thoracic Medicine. Analyses, interpretation of data and writing of the manuscript were funded from the Norwegian National Advisory Unit on Long-term Mechanical Ventilation.

\section{Availability of data and materials}

The datasets used and/or analysed during the current study are available from the corresponding author upon reasonable request.

\section{Authors' contributions}

$H M$, in cooperation with SL, RMN and GKN, designed and planned the study. HM drafted the manuscript. RMN supervised the analyses and results. SL interpreted the results and revised the manuscript for important critical content. RMN and GKN revised the manuscript for important critical content. All authors read and approved the final manuscript.

\section{Ethics approval and consent to participate}

The study has been approved by the Norwegian Regional Committee for Medical and Health Research Ethics (number 273.06 and 2012/1090-11) and by the Norwegian Centre for Research Data (project number 16001). At baseline in 2008, the patients in the Norwegian LTMV registry in West Norway were contacted by post and asked to participate in the study. In an information letter it was informed that the data would be stored for a possible follow-up study. Consent to participate in the study was considered by returning of the filled out questionnaires. In the follow-up study there was a written consent to allow register connection between the registers. For cohort patients who died, exemption from the consent requirement for register connection to the Norwegian Patient Registry and Cause of Death Register was given from the Regional Committee for Medical and Health Research Ethics.

Data from the Norwegian Patient Register has been used in this publication. The interpretation and reporting of these data are the sole responsibility of the authors, and no endorsement by the Norwegian Patient Register is intended nor should be inferred.

Consent for publication

Not applicable.

\section{Competing interests}

No conflicts of interest have been declared by the authors.

\section{Publisher's Note}

Springer Nature remains neutral with regard to jurisdictional claims in published maps and institutional affiliations.

\section{Author details \\ ${ }^{1}$ The Norwegian National Advisory Unit on Longterm Mechanical Ventilation, Department of Thoracic Medicine, Haukeland University Hospital, Jonas Lies vei 65, N-5021 Bergen, Norway. ${ }^{2}$ Department of Global Public Health and Primary Care, University in Bergen, Kalfarveien 31, 5018 Bergen, Norway. ${ }^{3}$ Department of Clinical Science, University in Bergen, Bergen, Norway. ${ }^{4}$ Faculty of Health and Social Sciences, Western Norway University of Applied Sciences, Inndalsveien 28, 5063 Bergen, Norway.}

Received: 20 June 2018 Accepted: 17 December 2018 Published online: 11 January 2019

\section{References}

1. Laghi F, Tobin M. Indication for mechanical ventilation. In: Tobin MJ, editor. Principles and Practice of Mechanical Ventilation. Third ed: Published by the McGraw-Hills companies, New-York, ISBN 978-0-07-173626-8; 2013. p. 113.

2. Windisch W. Home mechanical ventilation. In: Tobin MJ, editor. Principles and Practice of Mechanical Ventilation. Third ed: Published by the McGrawHills companies, New-York, ISBN 978-0-07-173626-8; 2013. p. 683-98.

3. Simonds AK. Home mechanical ventilation: an overview. Annals of the American Thoracic Society. 2016;13(11):2035-44. https://doi.org/10.1513/ AnnalsATS.201606-454FR. 
4. The Norwegian Directorate of Health. National guidelines for long-term mechanical ventilation (LTMV). ISBN-nr.978-82-8081-245-2. 2012. Available from URL: https://helsedirektoratet.no/retningslinjer/nasjonal-faglig-retningslinje-forlangtids-mekanisk-ventilasjon-ltmv. Accessed 6 Oct 2015.

5. Dretzke J, Moore D, Dave C, Mukherjee R, Price MJ, Bayliss S, et al. The effect of domiciliary noninvasive ventilation on clinical outcomes in stable and recently hospitalized patients with COPD: a systematic review and metaanalysis. Int J Chron Obstruct Pulmon Dis. 2016;11:2269-86. https://doi.org/ 10.2147/COPD.S104238.

6. Duiverman ML. Noninvasive ventilation in stable hypercapnic COPD: what is the evidence? ERJ Open Res. 2018;4(2):00012-2018. https://doi.org/10.1183/ 23120541.00012-2018.

7. Kohnlein T, Windisch W, Kohler D, Drabik A, Geiseler J, Hartl S, Karg O, LaierGroeneveld G, Nava S, Schönhofer B, Schucher B, Wegscheider K, Criée CP, Welte T. Non-invasive positive pressure ventilation for the treatment of severe stable chronic obstructive pulmonary disease: a prospective, multicentre, randomised, controlled clinical trial. Lancet Respir Med. 2014;2: 698-705. https://doi.org/10.1016/S2213-2600(14)70153-5.

8. Murphy PB, Rehal S, Arbane G, Bourke S, Calverley PMA, Crook AM, Dowson L, Duffy N, Gibson GJ, Hughes PD, Hurst JR, Lewis KE, Mukherjee R, Nickol A, Oscroft N, Patout M, Pepperell J, Smith I, Stradling JR, Wedzicha JA, Polkey MI, Elliott MW, Hart N. Effect of home noninvasive ventilation with oxygen therapy vs oxygen therapy alone on hospital readmission or death after an acute COPD exacerbation: a randomized clinical trial. JAMA. 2017:317(21): 2177-86. https://doi.org/10.1001/jama.2017.4451.

9. Bourke SC, Tomlinson M, Williams TL, Bullock RE, Shaw PJ, Gibson GJ. Effects of non-invasive ventilation on survival and quality of life in patients with amyotrophic lateral sclerosis: a randomised controlled trial. Lancet Neurol. 2006;5(2):140-7. https://doi.org/10.1016/S1474-4422(05)70326-4.

10. Laub M, Midgren B. Survival of patients on home mechanical ventilation: a nationwide prospective study. Respir Med. 2007;101:1074-8. https://doi.org/ 10.1016/.j.rmed.2006.10.007.

11. Olofson J, Dellborg C, Sullivan M, Midgren B, Caro O, Bergman B. Quality of life and palliation predict survival in patients with chronic alveolar hypoventilation and nocturnal ventilatory support. Qual Life Res. 2009;18: 273-80. https://doi.org/10.1007/s11136-009-9445-7.

12. Annane D, Orlikowski D, Chevret S. Nocturnal mechanical ventilation for chronic hypoventilation in patients with neuromuscular and chest wall disorders. Cochrane Database Syst Rev. 2014. https://doi.org/10.1002/ 14651858.CD001941.

13. Tan GP, McArdle N, Dhaliwal SS, Douglas J, Rea CS, Singh B. Patterns of use, survival and prognostic factors in patients receiving home mechanical ventilation in Western Australia: a single Centre historical cohort study. Chron Respir Dis. 2018;1:1479972318755723. https://doi.org/10.1177/1479972318755723.

14. Bach JR, Martinez D. Duchenne muscular dystrophy: continuous noninvasive Ventilatory support prolongs survival. Respir Care. 2011;56(6):744-50. https:// doi.org/10.4187/respcare.00831

15. Berlowitz DJ, Howard ME, Fiore JF, Vander Hoorn S, O'Donoghue FJ, Westlake J, Smith A, Beer F, Mathers S, Talman P. Identifying who will benefit from non-invasive ventilation in amyotrophic lateral sclerosis/motor neurone disease in a clinical cohort. J Neurol Neurosurg Psychiatry. 2015; 87(3):280-6. https://doi.org/10.1136/jnnp-2014-310055.

16. Boussaïd G, Lofaso F, Santos DB, Vaugier I, Pottier S, Prigent H, Bahrami S, Orlikowski D. Impact of invasive ventilation on survival when non-invasive ventilation is ineffective in patients with Duchenne muscular dystrophy: a prospective cohort. Respir Med. 2016;115:26-32. https://doi.org/10.1016/j. rmed.2016.04.009.

17. Budweiser S, Riedl SG, Jörres RA, Heinemann F, Pfeifer M. Mortality and prognostic factors in patients with obesity-hypoventilation syndrome undergoing noninvasive ventilation. J Intern Med. 2007c;261(4):375-83. https://doi.org/10.1111/j.1365-2796.2007.01765.x.

18. Borel JC, Burel B, Tamisier R, Dias-Domingos S, Baguet JP, Levy P, Pepin JL. Comorbidities and mortality in hypercapnic obese under domiciliary noninvasive ventilation. PLoS One. 2013:8(1):e52006. https://doi.org/10.1371/ journal.pone.0052006.

19. Ojeda Castillejo E, de Lucas Ramos P, López Martin S, Resano Barrios P, Rodríguez P, Morán Caicedo L, Bellón Cano JM, Rodriguez Gonzalez-Moro JM. Noninvasive mechanical ventilation in patients with obesity hypoventilation syndrome. Long-term outcome and prognostic factors. Arch Bronconeumol. 2015;51:61-8. https://doi.org/ 10.1016/j.arbres.2014.02.015.
20. Blankenburg T, Benthin C, Pohl S, Bramer A, Kalbitz F, Lautenschläger C, Schütte W. Survival of Hypercapnic patients with COPD and obesity hypoventilation syndrome treated with high intensity non invasive ventilation in the daily routine care. Open Respir Med J. 2017;30(11):31-40. https://doi.org/10.2174/1874306401711010031.

21. Jäger L, Franklin KA, Midgren B, Löfdahl K, Ström K. Increased survival with mechanical ventilation in post-tuberculosis patients with the combination of respiratory failure and chest wall deformity. Chest. 2008;133:156-60. https://doi.org/10.1378/chest.07-1522.

22. Marti S, Pallero M, Ferrer J, Rios J, Rodriguez E, Morell F, Munoz X. Predictors of mortality in chest wall disease treated with noninvasive home mechanical ventilation. Respir Med. 2010;104(12):1843-9. https://doi.org/10. 1016/j.rmed.2010.08.013.

23. Cano NJ, Pichard C, Court-Fortune I, Costes F, Cynober L, GérardBoncompain M, Molano LC, Cuvelier A, Laaban JP, Melchior JC, Raphaël JC, France J, Lloret T, Roth H, Pison C. Survival of patients with chronic respiratory failure on long-term oxygen therapy and or non-invasive ventilation at home. Clin Nutr. 2015;34(4):739-44. https://doi.org/10.1016/j. clnu.2014.08.011.

24. Idler EL, Benyamini Y. Self-rated health and mortality: a review of twentyseven community studies. J Health Soc Behav. 1997;38(1):21-37 PMID: 9097506.

25. Quinten C, Coens C, Mauer M, Comte S, Sprangers MA, Cleeland C, et al. Baseline quality of life as a prognostic indicator of survival: a meta-analysis of individual patient data from EORTC clinical trials. Lancet Oncol. 2009;10: 865-71. https://doi.org/10.1016/S1470-2045(09)70200-1.

26. Carone M, Antoniu S, Baiardi P, Digilio VS, Jones PW, Bertolotti G. Predictors of mortality in patients with COPD and chronic respiratory failure: the quality-of-life, evaluation and survival study (QuESS). COPD. 2016;13:130-8. https://doi.org/10.3109/15412555.2015.1067294.

27. Furukawa $T$, Taniguchi $H$, Ando M, Kondoh Y, Kataoka K, Nishiyama O, Johkoh T, Fukuoka J, Sakamoto K, Hasegawa Y. The St. George's respiratory questionnaire as a prognostic factor in IPF. Respir Res. 2017;18(1):18. https:// doi.org/10.1186/s12931-017-0503-3.

28. Windisch W, Freidel B, Schucher $\mathrm{H}$, Baumann $M$, Wiebel $H$, Matthys $H_{\text {, }}$ Petermann $F$. The severe respiratory insufficiency (SRI) questionnaire: a specific measure of health-related quality of life in patients receiving home mechanical ventilation. J Clin Epidemiol. 2003;56(8):752-9. https://doi.org/10 1016/S0895-4356(03)00088-X.

29. Budweiser S, Hitzl AP, Jörres RA, Schmidbauer K, Heinemann F, Pfeifer M. Health-related quality of life and long-term prognosis in chronic hypercapnic respiratory failure: a prospective survival analysis. Respir Res. 2007a;8(1):92. https://doi.org/10.1186/1465-9921-8-92.

30. Oga T, Taniguchi H, Kita H, Tsuboi T, Tomii K, Ando M, Kojima E, Tomioka H, Taguchi Y, Kaji Y, Maekura R, Hiraga T, Sakai N, Kimura T, Mishima M, Chin K. Analysis of the relationship between health status and mortality in hypercapnic patients with noninvasive ventilation. Clin Respir J. 2015;11(6): 772-80. https://doi.org/10.1111/cri.12415.

31. Norwegian register for long-term mechanical ventilation. Available at: https://www.kvalitetsregistre.no/registers/nasjonalt-register-langtidsmekanisk-ventilasjon. Accessed 10 Nov 2017.

32. The Norwegian Patient Registry. The Norwegian Directorate of Health. Available at: https://helsedirektoratet.no/english/norwegian-patient-registry. Accessed 10 Nov 2016.

33. Norwegian Cause of Death Registry. The Norwegian Institute of Public Health, Available at: https://www.fhi.no/en/hn/health-registries/cause-ofdeath-registry/. Accessed 10 Nov 2015.

34. Markussen H, Lehmann S, Nilsen RM, Natvig GK. The Norwegian version of the severe respiratory insufficiency questionnaire. Int J Nurs Pract. 2015; 21(3):229-38. https://doi.org/10.1111/ijn.12256.

35. Markussen H, Lehmann S, Nilsen RM, Natvig GK. J Adv Nurs. 2018;74(3):65165. https://doi.org/10.1111/jan.13472.

36. López-Campos JL, Failde I, Masa JF, Benítez-Moya JM, Barrot E, Ayerbe R, León-Jiménez A, Windisch W. Transculturally adapted Spanish SRI questionnaire for home mechanically ventilated patients was viable, valid, and reliable. J Clin Epidemiol. 2008;61(10):1061-6. https://doi.org/10.1016/j. jclinepi.2007.09.002.

37. Ghosh D, Rzehak P, Elliott MW, Windisch W. Validation of the english severe respiratory insufficiency questionnaire. Eur Respir J. 2012;40(2):408-15. https://doi.org/10.1183/09031936.00152411.

38. Oga T, Taniguchi H, Kita H, Tsuboi T, Tomii K, Ando M, Kojima E, Tomioka H, Taguchi Y, Kaji Y, Maekura R, Hiraga T, Sakai N, Kimura T, Mishima M, 
Windisch W, Chin K. Validation of the Japanese severe respiratory insufficiency questionnaire in hypercapnic patients with noninvasive ventilation. Respir Investig. 2017:166-72. https://doi.org/10.1016/j.resinv. 2016.12.003.

39. Ribeiro C, Ferreira D, Conde S, Oliveira P, Windisch W. Validation of the Portuguese severe respiratory insufficiency questionnaire for home mechanically ventilated patients. Rev Port Pneumol. 2017;23(3):139-45 https://doi.org/10.1016/j.rppnen.2017.01.001.

40. Chen R, Guan L, Wu W, Yang Z, Li X, Luo Q, Liang Z, Wang F, Guo B, Huo Y, Yang $Y$, Zhou $L$. The Chinese version of the severe respiratory insufficiency questionnaire for patients with chronic hypercapnic chronic obstructive pulmonary disease receiving non-invasive positive pressure ventilation. BMJ Open. 2017;7(8):e017712. https://doi.org/10.1136/bmjopen-2017-017712.

41. Adler D, Rabec C, Janssens J-P. Home monitoring and follow-up of longterm NIV. In: Simonds AK, editor. Practical handbook of noninvasive ventilation: European Respiratory Society, ISBN 978-1-84984-075-0; 2015.

42. Struik FM, Kerstjens HAM, Bladder G, Sprooten R, Zijnen M, Asin J, Van der Molen T, Wijkstra PJ. The severe respiratory insufficiency questionnaire scored best in the assessment of health-related quality of life in chronic obstructive pulmonary disease. J Clin Epidemiol. 2013;66(10):1166-74. https://doi.org/10.1016/j.jclinepi.2013.04.013.

43. Windisch W. Impact of home mechanical ventilation on health-related quality of life. Eur Respir J. 2008;32:1328-36. https://doi.org/10.1183/ 09031936.00066407.

44. Rawshani A, Svensson AM, Zethelius B, Eliasson B, Rosengren A, Gudbjörnsdottir S. Association between socioeconomic status and mortality, cardiovascular disease, and Cancer in patients with type 2 diabetes. JAMA Intern Med. 2016;176(8):1146-54. https://doi.org/10.1001/jamainternmed. 2016.2940

45. Chio A, Calvo A, Ghiglione P, Mazzini L, Mutani R, Mora G. Tracheostomy in amyotrophic lateral sclerosis: a 10-year population-based study in Italy. J Neurol Neurosurg Psychiatry. 2010;81:1141e1143. https://doi.org/10.1136/ jnnp.2009.175984.

46. Budweiser S, Harlacher M, Pfeifer M, Jörres RA. Co-morbidities and hyperinflation are independent risk factors of all-cause mortality in very severe COPD. J Chronic Obstructive Pulmonary Disease. 2014;11(4):388-400. https://doi.org/10.3109/15412555.2013.83617.

47. Tangvik RJ, Tell GS, Eisman JA, Guttormsen AB, Henriksen A, Nilsen RM, Øyen J. Ranhoff. The nutritional strategy: four questions predict morbidity, mortality and health care costs. AH. Clin Nutr. 2014;33(4):634-41. https://doi. org/10.1016/j.clnu.2013.09.008.

48. Palm A, Midgren B, Janson C, Lindberg E. Gender differences in patients starting long-term home mechanical ventilation due to obesity hypoventilation syndrome. Respir Med. 2017;124:104-105. DOl: https://doi. org/10.1016/j.rmed.2017.02.003

49. Ishikawa Y, Miura T, Ishikawa Y, Aoyagi T, Ogata H, Hamada S, Minami R. Duchenne muscular dystrophy: survival by cardio-respiratory interventions. Neuromuscul Disord. 2011;21:47-51. https://doi.org/10.1016/..nmd.2010.09.006.

50. Depuydt P, Oeyen S, De Smet S, De Raedt S, Benoit D, Decruyenaere J, Derom E. Long-term outcome and health-related quality of life in difficultto-wean patients with and without ventilator dependency at ICU discharge: a retrospective cohort study. BMC Pulmonary Medicine 2016;27;16 (1):133. DOI: https://doi.org/10.1186/s12890-016-0295-0.

51. Huttmann SE, Windisch W, Storre JH. Invasive home mechanical ventilation: living conditions and health-related quality of life. Respiration. 2015;89(4): 312-21. https://doi.org/10.1159/000375169.

52. Jylha M. What is self-rated health and why does it predict mortality? Towards a unified conceptual model. Soc Sci Med. 2009;69:307-16. https:// doi.org/10.1016/j.socscimed.2009.05.013.

53. Lerum SV, Solbrække KN, Holmøy T, Frich J. Unstable terminality: negotiating the meaning of chronicity and terminality in motor neurone disease. Sociol Health IIIn 2015; Vol. 37 0141-9889, pp. 81-96 DOI: https:// doi.org/10.1111/1467-9566.12182

54. Charlson ME, Pompei P, Ales KL, Mackenzie CR. A new method of classifying prognostic co-morbidity in longitudinal studies: development and validation. J Chronic Dis. 1987;40:373-83.

\section{Ready to submit your research? Choose BMC and benefit from:}

- fast, convenient online submission

- thorough peer review by experienced researchers in your field

- rapid publication on acceptance

- support for research data, including large and complex data types

- gold Open Access which fosters wider collaboration and increased citations

- maximum visibility for your research: over $100 \mathrm{M}$ website views per year

At BMC, research is always in progress.

Learn more biomedcentral.com/submissions 